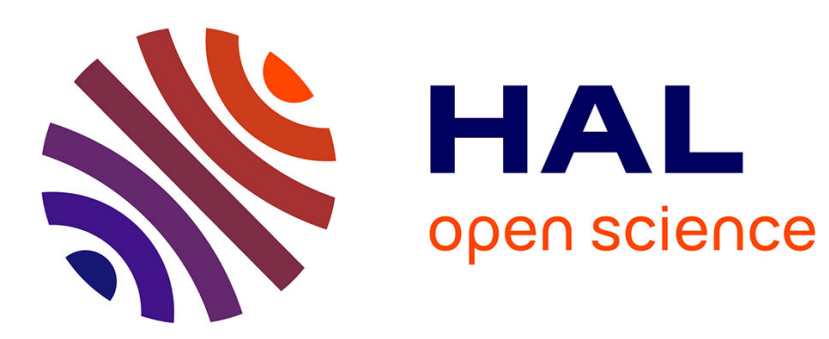

\title{
Modeling and Evaluation of HE Driven Shock Effects In Copper with the MTS Mode1
}

\author{
M. Murphy, D. Lassila
}

\section{To cite this version:}

M. Murphy, D. Lassila. Modeling and Evaluation of HE Driven Shock Effects In Copper with the MTS Mode1. Journal de Physique IV Proceedings, 1997, 07 (C3), pp.C3-655-C3-661. 10.1051/jp4:19973112 . jpa-00255397

\section{HAL Id: jpa-00255397 https://hal.science/jpa-00255397}

Submitted on 1 Jan 1997

HAL is a multi-disciplinary open access archive for the deposit and dissemination of scientific research documents, whether they are published or not. The documents may come from teaching and research institutions in France or abroad, or from public or private research centers.
L'archive ouverte pluridisciplinaire HAL, est destinée au dépôt et à la diffusion de documents scientifiques de niveau recherche, publiés ou non, émanant des établissements d'enseignement et de recherche français ou étrangers, des laboratoires publics ou privés. 


\title{
Modeling and Evaluation of HE Driven Shock Effects In Copper with the MTS Model
}

\author{
M.J. Murphy and D.H. Lassila
}

Lawrence Livermore National Laboratory, P.O. Box 808, 282 Livermore, CA 94550, U.S.A.

\begin{abstract}
Many experimental studies have investigated the effect of shock pressure on the post-shock mechanical properties of OFHC copper. These studies have shown that significant hardening occurs during shock loading due to dislocation processes and twinning. It has been demonstrated that when an appropriate initial value of the Mechanical Threshold Stress (MTS) is specified, the post-shock flow stress of OFE copper is well described by relationships derived independently for unshocked materials. In this study we consider the evolution of the MTS during HE driven shock loading processes and the effect on the subsequent flow stress of the copper. An increased post shock flow stress results in a higher material temperature due to an increase in the plastic work. An increase in temperature leads to thermal softening which reduces the flow stress. These coupled effects will determine if there is melting in a shaped charge jet or a necking instability in an EFP liner. The critical factor is the evolution path followed combined with the "current" temperature, plastic strain, and strain rate. Preliminary studies indicate that in simulations of HE driven shock processes with very high resolution zoning, the MTS saturates because of the rate dependence in the evolution law. On going studies are addressing this and other issues with the goal of developing a version of the MTS model that treats HE driven shock loading, temperature, strain, and rate effects apriori.
\end{abstract}

\begin{abstract}
Résumé. De nombreuses études expérimentales ont recherché l'effet de la pression de l'onde de choc sur les propriétés mécaniques post-impact du cuivre OFHC. Ces études ont montré qu'un durcissement important a lieu pendant l'impact à cause des processus de dislocation et de maclage. Nous avons montré que quand une valeur initiale appropriée de contraintes de seuil mécanique (MTS) est spécifiée, les contraintes de fluage post-impact du cuivre OFE sont bien décrites par les rapports dérivés indépendamment pour les matériaux sans impact. Dans cette étude, nous considérons l'évolution des MTS pendant les processus d'application de charge d'impact par charge explosive élevée et les effets sur les contraintes de fluages ultérieures du cuivre. Une augmentation des contraintes de fluage post-impact provoque une température plus élevée du matériau causée par l'augmentation de la déformation plastique. Une augmentation de la température provoque un recuit thermique qui réduit les contraintes de fluage. Ces effets associés déterminent s'il y a une fonte dans un jet de charge creuse ou une instabilité de striction dans une chemise en EFP. Le facteur critique est le passage d'évolution suivi combiné à la température « courante ", le fluage plastique et le taux de fluage. Des études préliminaires indiquent que, dans des simulations de processus d'impact à charge explosive avec découpage en zones de haute résolution, les MTS saturent à cause du taux de dépendance de la loi de l'évolution. Des recherches de longue durée étudient ce sujet et d'autres questions ayant pour objet de développer une version du modèle de MTS qui traite a priori des effets de la charge, de la température, du fluage et des taux.
\end{abstract}

\section{INTRODUCTION}

This paper addresses the post shock flow stress of copper in the context of hydrocode modeling with the Mechanical Threshold Stress (MTS) model [1-4]. Several experimental studies have investigated the effect of shock pressure and duration on the post-shock mechanical properties of copper [5-7]. These studies have shown that significant hardening occurs during shock loading due to dislocation processes and twinning. Hardening due to shock loading can be accounted for in the MTS model when an appropriate initial value of the MTS is specified $[5,8]$. The post-shock flow stress of OFE copper is then well described by relationships derived independently for unshocked materials. Unfortunately, for several reasons, we are not able to completely evaluate the shocked behavior of a material while still in its shocked condition or state (i.e. just after the shock passes). The best we can currently do is a) recover a shocked material specimen and evaluate it in its recovered state, b) evaluate wave profiles of shocked materials while still in the shocked state and c) evaluate the flow stress controlled deformation behavior of shocked materials while still in the shocked state. 
The subject of this paper is on using the MTS model in an explicit hydrocode to evaluate the flow stress controlled deformation behavior of shocked materials while still in the shocked state. We are concerned with what is required to more accurately model the post-shock behavior of a copper EFP liner for the several micro-seconds of inertial deformation that follow high explosive shock loading. Specifically, we are using DYNA2D simulations of high explosive loaded EFP liners to evaluate the utility of the MTS model in this very high strain rate environment.

We consider the evolution of the MTS during and after a shock loading process and its effect on the subsequent flow stress of the copper liner. An increased post shock flow stress will result in a higher material temperature for a given amount of strain due to an increase in the plastic work (i.e. area under the stress-strain curve). An increase in temperature leads to thermal softening which reduces the flow stress, These coupled effects will determine if there is melting in a shaped charge jet or a necking instability in an explosively formed projectile (EFP). With the MTS model, the critical factor is the temperature-strainstrain rate path followed, combined with the "current" temperature and strain rate. Plastic strain does not "explicitly" enter into this formulation.

\section{MTS MODEL IMPLEMENTATION IN EXPLICIT HYDROCODE}

We use the MTS model adjusted by the temperature and pressure dependent shear modulus to determine the flow stress [9]. Using this form of the model, the flow stress is given by,

$$
\sigma=\hat{\sigma}_{\mathrm{a}} \cdot \mathrm{M}(\mathrm{t})+\left(\hat{\sigma}-\hat{\sigma}_{\mathrm{a}}\right) \cdot \mathrm{M}(\mathrm{t})\left\{1-\left[\frac{\mathrm{kT}}{\mathrm{G}_{0}} \ln \left(\dot{\varepsilon}_{0} / \dot{\varepsilon}^{\mathrm{p}}\right)\right]^{1 / \mathrm{q}}\right\}^{1 / \mathrm{p}}
$$

where, $M(t)$ is the temperature and pressure dependent shear modulus and the mechanical threshold stress. $\hat{\sigma}$, is an internal state variable. Discussion and definitions of the other values used in the model art described in detail elsewhere [5-7]. The thermally activated portion of the MTS evolves as a function of the current value of the MTS, $\hat{\sigma}$, the temperature, T, and the plastic strain, $\varepsilon^{\mathrm{p}}$. The change in the MTS. $\hat{\sigma}$, with plastic strain, $\varepsilon^{\mathrm{p}}$, is given by

$$
\delta \hat{\sigma} / \delta \varepsilon^{p}=\Theta_{0}\left[1-\mathrm{F}\left(\hat{\sigma} / \hat{\sigma}_{\mathrm{s}}\right)\right]
$$

where $\Theta_{0}$ follows the form of Maudlin et al [10]

$$
\Theta_{0}=a_{0}+a_{1} \ln \left(\dot{\varepsilon}^{\mathrm{p}}\right)+\mathrm{a}_{2} \sqrt{\dot{\varepsilon}^{\mathrm{p}}}
$$

with the empirical function $F$ given elsewhere [5-7]. In the explicit hydrocode implementation of the MTS model, the incremental change in $\hat{\sigma}$ comes from rearranging equation 2

$$
\Delta \hat{\sigma}=\left(a_{0}+a_{1} \ln \left(\dot{\varepsilon}^{p}\right)+a_{2} \sqrt{\dot{\varepsilon}^{p}}\right) \cdot\left[1-F\left(\hat{\sigma} / \hat{\sigma}_{s}\right)\right] \cdot \dot{\varepsilon}^{p} \cdot d t
$$

where $\dot{\varepsilon}^{\mathrm{p}}$ is the plastic strain rate and dt is the time step of the current cycle in the hydrocode analysis.

\section{COPPER MATERIAL PROPERTIES}

In previous studies, we have determined appropriate sets of material properties (for the Steinberg-Guin: Johnson-Cook, and Zerilli-Armstrong material models [11-14]) for an explosively loaded copper EF? liner $[15,16]$. The material model parameters were "calibrated" by matching to shadowgraphs of t: 
fully deformed projectile shapes derived from experiments of four different generic EFP warhead designs with the same liner material. The EFP warhead had an $89 \mathrm{~mm}$ diameter, L/D of 0.5 , with $300 \mathrm{~g}$ of LX-14, and $82 \mathrm{~g}$ copper liner. The liner material was fabricated using a multi-step forge/anneal/coin process. The starting OFHC copper material was a thick disk machined from ASTM-B-153 half hard bar stock. The forging process transformed the $20 \mathrm{~mm}$ thick by $25 \mathrm{~mm}$ diameter disk of copper into an $89 \mathrm{~mm}$ diameter flat plate with the desired liner thickness profile. The plate was annealed, followed by a multistep coining process to achieve the desired liner curvature. The grain size ranged from $15 \mu$ to $20 \mu$.

\section{EFP ANALYSIS WITH MTS MODEL}

In this study we are concerned with what is required to more accurately model the post-shock behavior of the copper EFP liner for the several micro-seconds of inertial deformation that follow the high explosive shock loading. However, to accurately model the post-shock behavior of a material, we should also treat the behavior of the material during the shock loading. We feel that the MTS model is well suited for this task as it allows for the possibility of evolving the MTS as a function of the shock loading conditions as well as the temperature and plastic strain.

When using the MTS model with published material properties, the calculated final EFP projectile shape is under deformed. In general, this is an indication that the average flow stress is too high. This high flow stress effect is consistent with results we have seen when using other material models in the EFP liner deformation problem. In our other studies, the initial simulations using the "laboratory" determined material model parameters typically produce a projectile shape that has a shorter length and larger diameter projectile than what is observed experimentally $[15,16]$. A comparison of the final projectile shape and fringes of plastic strain using the MTS model and the previously calibrated Zerilli-Armstrong model (ZA) is shown in Figure $1 \mathrm{a}$ and $1 \mathrm{~b}$ respectively. The liner was simulated with 60 elements radially and 5 elements through the thickness. The black fringe level is plastic strain greater than $200 \%$ while the white fringe level is plastic strain less than $100 \%$. The projectile calculated with the MTS model is under deformed and has much less plastic strain than the ZA calculated projectile that matches the experiment. In the next section we discuss why the flow stress is too high in these explicit hydrocode simulations using the MTS model.

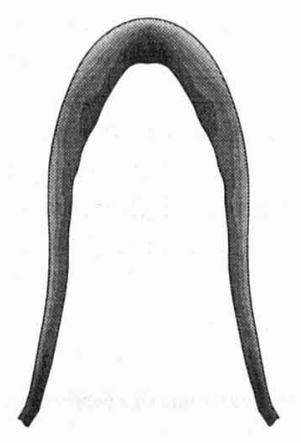

(a)

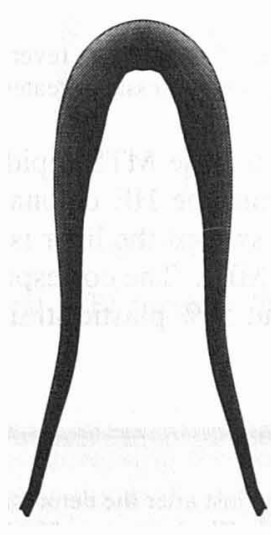

(b)

Figure 1: Comparison of projectile shape and fringes of plastic strain using the MTS model (a) and the previously "calibrated" Zerilli-Armstrong model (b). The black fringe level is plastic strain greater than $200 \%$ while white is less than $100 \%$. 


\section{HE DRIVEN SHOCK LOADING CONDITIONS}

In previous experimental and numerical studies looking at shock loading of shaped charge liners, we saw that pressure waves continue to reverberate in the liner after the detonation front has passed [17,18]. This same effect is shown in Fig. 2 for the EFP liner. In the lowest frame, the detonation front has just reached the liner and we see the initial shock (black fringe) as it propagates through the material. In the subsequent frames laid out from bottom to top, we see the interface of the detonation front with the liner move radially outward as the detonation wave sweeps radially along the liner. This initial shock from the detonation front propagates through the liner and reflects from the free surface as a rarefaction wave (light fringe). The spall suppressed calculated tensile pressure in the initial rarefaction wave has magnitude greater than $5 \mathrm{GPa}$ suggesting the possibility of material damage or microporosity. In the top frame, as the detonation wave has completely swept along the liner, we see multiple shock reverberation still ringing in the liner. The shock wave ringing in the liner causes very high levels of strain-rate ringing that can be observed in Figure 3. The black fringe color represents a strain rate of $2.0 \mathrm{e}+05$ per second or greater. Note that in the Follansbee and Kocks paper on the MTS model, the maximum strain rate of the experimental data used in the comparison and evaluation was only $1.0 \mathrm{e}+04$ per second.

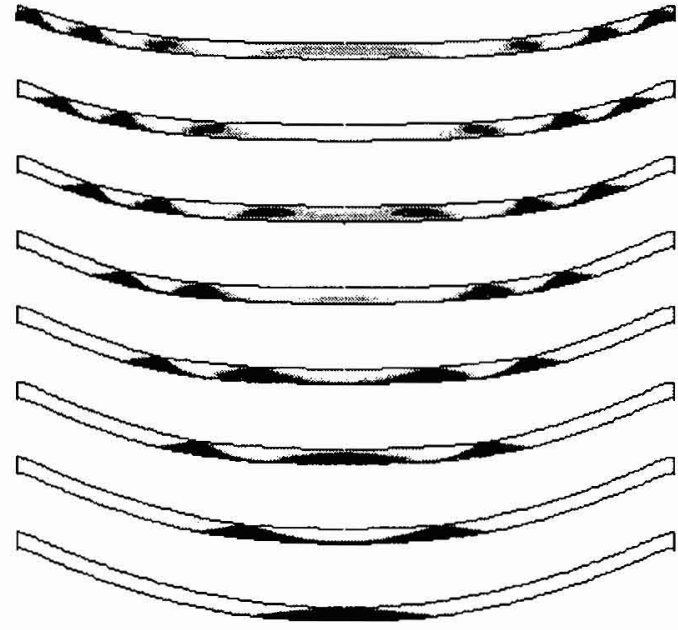

Figure 2: Description of shock wave reverberations in liner. Black fringe color is pressure greater than $20 \mathrm{GPa}$.

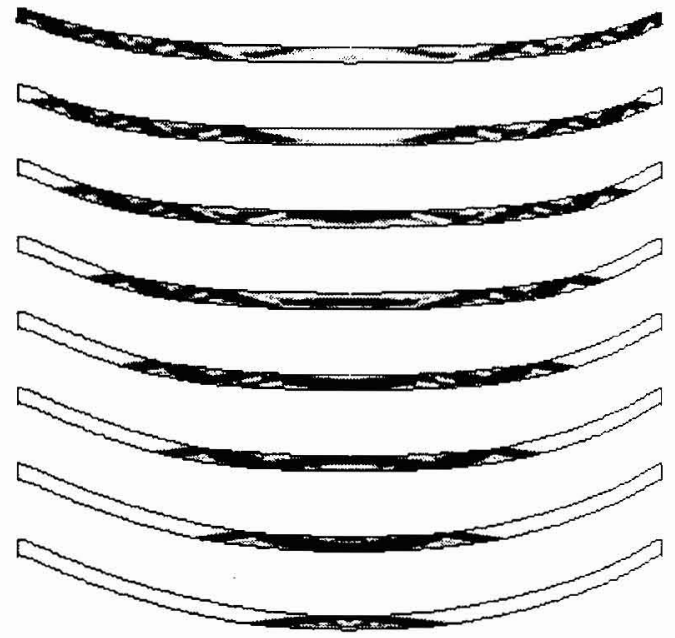

Figure 3: Description of strain rate reverberations in liner. Black fringe contour is $2.5 \mathrm{e}+5$ per second or greater.

We have found that the MTS rapidly approaches saturation during the strain rate ringing caused by the shock loading from the HE detonation. The resulting value of the nearly saturated MTS just after the detonation wave sweeps the liner is shown in Figure 4. The black fringe level shows a value of the MTS greater than $500 \mathrm{MPa}$. The corresponding plastic strain levels are shown in Figure 5 with the black fringe representing about $50 \%$ plastic strain.

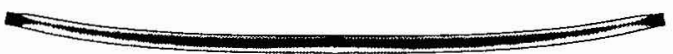

Figure 4: MTS value just after the detonation wave sweeps the EFP liner. Black fringe is $500 \mathrm{MPa}$.

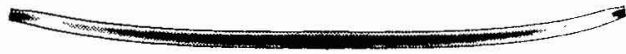

Figure 5: Plastic strain levels after detonation wave sweep the EFP liner. Black is $>47 \%$ and white is $<32 \%$ strain.

\section{DISCUSSION}

In the study of shock loading on shaped charge liners we concluded there was some material damage during the pressure wave reverberations but there was not sufficient time for a "spall" to develop [17]. The second and subsequent shocks recompress the expected microporosity created from the rarefaction of 
the previous shocks. With the EFP liner, the shock wave ringing and corresponding very high levels of strain rate ringing cause the MTS to become nearly saturated soon after the detonation wave has swept along the liner. We feel the MTS model in its present form does not treat this portion of the process correctly as the subsequent flow stress controlled deformation behavior of the EFP liner results in a shorter length - larger diameter projectile than observed experimentally. We feel that there are several reasons why the MTS model may not be suitable in its present form for treating the HE loaded deformation behavior of thin plates.

\subsection{Micro Voids and Dislocation Annihilation}

The basic problem we observe with the MTS model in the simulation of high explosive loading of EFP liners is the pressure wave reverberations that cause high strain rate reverberations. The high strain rate reverberations cause the MTS to saturate soon after the detonation wave passes. In the thin plate loading of liners, the high strain reverberations occur during alternating positive and negative (tensile) pressures. It is valid for the MTS to increase during the compressive shock portion of the reverberation but it is uncertain how it should evolve during the tensile pressure portion of the strain rate reverberation because of the well known Bauschinger effect. Both the very high strain rates and the very high strain rates with simultaneous high tensile pressure are beyond the scope of the current model. It is possible that we may need to hold constant or allow for some decrease in the MTS during the tensile pressure portion of the reverberation to account for the creation of micro-voids and the subsequent annihilation of dislocations.

As a purely hypothetical evaluation of this concept we modified the model to allow the MTS to increase during compressive pressure and then decrease using the same evolution law when the tensile pressure exceeded $500 \mathrm{MPa}$. This slightly improved the calculated shape of the projectile, but not enough to match the experimental shape. Frames (b) and (c) of Figure 6 show a comparison of the calculated projectile shape with the baseline MTS model and tensile pressure modified model. The calculated projectile shape with the calibrated ZA model is shown in frame (a).

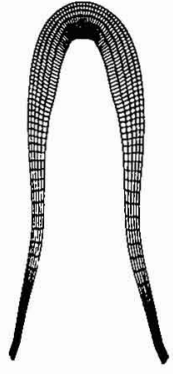

(a)

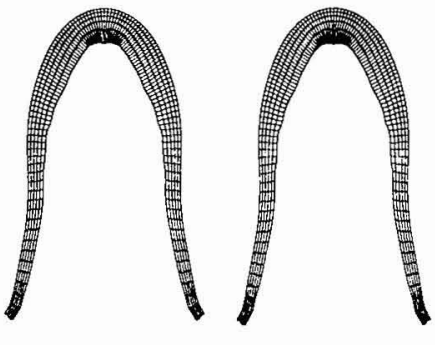

(b)

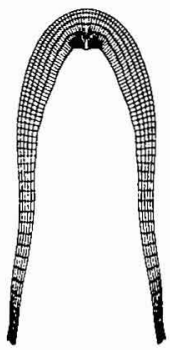

(d)

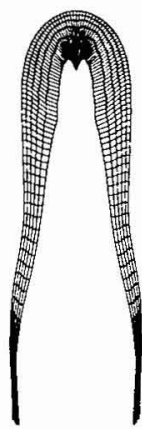

(e)

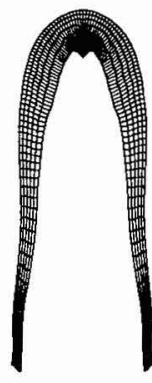

(f)

Figure 6: Comparison of calculated projectile shapes using hypothetical MTS model adjustments.

\subsection{Strain Rate Issues}

In the explicit hydrocode simulation of shock loading we see that by decreasing the zone size there is a increase in the corresponding maximum calculated strain rate. This does not really effect the total plastic strain as the time step is lower with the smaller zones and the strain rate - delta time product remains about constant. However, with the MTS model, the shock induced very high strain rates caused by high explosive loading is a problem because $\delta \hat{\sigma} / \mathrm{dt}$ is proportional to the strain rate to the three halves power as seen in equation 4. In the Follansbee and Kocks paper, it was proportional to the strain rate squared. This proportionality was found to be to stiff in strain rate and revised [10]. 
In another hypothetical evaluation of the effect of the very high strain rates, we ran the hydrocode analysis and limited the maximum strain rate used in the MTS model to $5.0 \mathrm{e}+04$ and $1.0 \mathrm{e}+04$ per sec. The projectile shapes from the two simulation are shown in frames (d) and (e) of Figure 6 . We could probably find a "maximum allowable" strain rate to use in the model that would match the shape of framie (a), but our goal is to develop a model that can treat the HE driven shock loading, temperature, strain, and rate effects apriori.

\subsection{Shock and Non-Shock MTS Evolution}

In one final hypothetical evaluation, we only allowed the MTS to evolve during the non-shock loading processes. Whenever the pressure was between negative $1 \mathrm{GPa}$ and positive $1 \mathrm{GPa}$ we allowed the MTS to evolve in the normal manner. When the pressure was below negative $1 \mathrm{GPa}$ or above positive $1 \mathrm{GPa}$, the MTS did not evolve and was held constant. This approach gave a fairly good match to the experimental data as shown in frame (f) of Figure 6. In fact, this projectile shape was closer to the experimental result than the projectile shape obtained with the "calibrated" ZA model. This is quite encouraging as it allows for the introduction of a shock MTS evolution model during the shock loading process when the standard (or non-shock) portion of the MTS is held constant and does not evolve.

\subsection{Strain Rate Smearing}

We have also looked at a "time smearing" of the strain rate by averaging it with the five previous cycles (a limitation of the number of history variables). This had virtually no effect as the period of oscillation of the strain rate ringing goes with the shock transit time through the liner. Maudlin suggested a "spatial smearing" of the strain rate by using a full tensor Q implementation [19]. This has not been evaluated.

\subsection{Temperature Effects from HE Detonation Products}

Since the MTS evolution equation has a temperature component in the empirical function $\mathrm{F}$, we have also evaluated whether heat conduction from the high temperature products of the explosive detonation could cause significant thermal softening during the total time the hot $\mathrm{HE}$ gas products are in contact with the copper liner (about $50 \mu \mathrm{sec}$ ). We found that significant heating does occur at the HE/liner interface but the depth of heating is only about 100 microns. This estimate is based on a CHEETAH calculation of the explosive products temperature (3000K initially to $1000 \mathrm{~K}$ at $50 \mu \mathrm{sec}$ ) and a transient one dimensional heat transfer analysis conducted with TOPAZ2D. The thermal softening from this heating is not sufficient to offset the saturation of the MTS from the strain rate ringing.

\section{SUMMARY AND CONCLUSIONS}

Our primary conclusion is that the MTS model in its present form does not correctly treat the high strain rate ringing that results from high explosive shock loading of thin plates. This is not totally unexpected as the MTS model was not developed to treat shock loading conditions. We see that more work needs to be done before we can apply it to the thin plate shock loading class of problems. We have shown that there is room for implementing a shock MTS evolution model in conjunction with the standard (or non-shock) MTS model using pressure as a screening parameter to change between modes. On going studies are addressing this and other issues with the goal of developing a version of the MTS model that treats the very high strain rates and pressure reverberations observed in HE driven shock loading of thin plates.

\section{REFERENCES}

1. Follansbee, P. S. High-strain-rate deformation of FCC metals and alloys. In Metallurgicil Applications of Shock Waves and High Strain Rate Phenomena. Editors: L. E. Murr, K. P. Staudhammer, and M. A. Meyers. Ch. 24, p. 451. Marcell Dekker, N.Y., 1986. 
2. Follansbee, P. S., Kocks, U. F., A constitutive description of the deformation of copper based on the use of mechanical threshold stress as an internal state variable, Acta Met, 36, 81-93, 1988.

3. Maudlin, P. J., et al., Implementation and assessment of the mechanical-threshold-stress model using EPIC2 and PINON computer codes. Los Alamos National Laboratory, LA-11895-MS, 1990.

4. Gourdin, W. H., Lassila, D. H., Flow stress of OFE copper at strain rates from $10^{-3}$ to $10^{4} \mathrm{~s}^{-1}$ : grain size effects and comparison to the mechanical threshold stress model. Acta Met, 39, 2337-2348, 1991.

5. Gray, G. T., Follansbee, P. S., Influence of peak pressure and pulse duration on the substructure development and threshold stress measurements in shock loaded copper, Proc. Int. Conf. On Impact Loading and Dynamic Behaviour of Materials, Bremen, 1987.

6. Lassila, D. H. et al., High strain rate deformation behavior of shocked copper. Int. Conf. On ShockWave and High Strain Rate Phenomena in Materials, San Diego, 1990.

7. Gourdin, W. H., Lassila, D. H., The mechanical behavior of pre-shocked copper at strain rates of $10^{-3}$ to $10^{4} \mathrm{~s}^{-1}$ and temperatures of 25-400 degrees C. Mat. Sci. \& Eng. A151, 11-18, 1992.

8. W.H. Gourdin and D.H. Lassila, "Deformation Behavior of Pre-Shocked Copper as a Function of Strain Rate and Temperature", UCRL-JC-106130, presented at APS 1991 Topical Conference on Shock Compression of Condensed Matter, Williamsburg, VA June 17-20, 1991.

9. Steinberg, D. J., Equation of state and strength properties of selected materials, Lawrence Livermore National Laboratory, UCRL-MA-106, 1991.

10. Maudlin, P. J. et al, A continuum mechanics code analysis of steady plastic wave propagation in the taylor test. Int. J. Impact Eng., 3, 231-256, 1997.

11. Steinberg, D. J., Guinan, M. W., A high-strain-rate constitutive model for metals. Lawrence Livermore National Laboratory, UCRL-80465, 1978.

12. Johnson, G. R., Cook, W. H., A constitutive model and data for metals subjected to large strains, high strain rates, and high temperature," 7th Int. Symp. on Ballistics, 1983.

13. Zerilli, F. J., Armstrong, R. W., Dislocation-Mechanics-Based constitutive relations for material dynamics calculations", J. Appl. Phys., 61, (5), 1816, 1987.

14. Zerilli, F. J., Armstrong, R. W., Dislocation mechanics based analysis of material dynamics behavior", J. de Physique, 49, C3, 529, 1988.

15. Murphy, M. J., Constitutive model parameter determination from generic EFP warhead tests", J de Physique IV, Colloque C8, Vol 4, 483, 1994.

16. Murphy, M. J., Baker, E. L., Using nonlinear optimization methods to reverse engineer liner material properties from EFP tests", $15^{\text {th }}$ Int Symp on Ballistics, 1995.

17. Murphy, M.J. et al, Examination of shaped charge liner shock loading, $16^{\text {th }}$ Int Symp on Blstcs. 1996.

18. Simonson, S. C. et al, Fabry-Perot measurements and analysis of TOW-2A liner collapse and jet formation. $16^{\text {th }}$ Int Symp on Ballistics, 1996.

19. Maudlin, P. J., personal communication.

This work was performed under the auspices of the U.S. Department of Energy by Lawrence Livermore

National Laboratory under Contract W- 7405-Eng-48. 